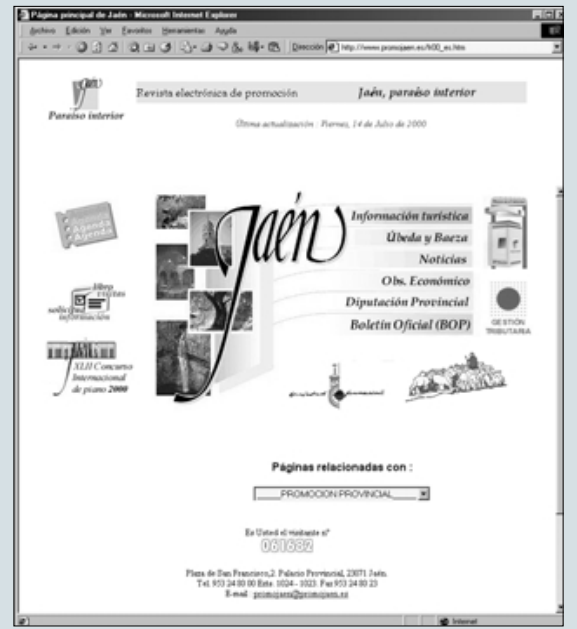

tivas y cuidadas, de los monumentos de Úbeda, sus autores, elementos arquitectónicos, etc., siempre situándolos en su espacio geográfico y relacionándolos con su entorno.

Por otro lado, la página http://www.spa.es/turismo/spain/jae.htm/, realizada en colaboración con los ayuntamientos correspondientes, ofrece guías turísticas de las ciudades de Jaén, Úbeda y Baeza en las que, además de toda aquella información y datos prácticos que en general interesan al viajero, se facilita el acceso a una breve pero completa información de algunos de los monumentos de las tres ciudades. Junto a cada texto aparece un icono que se debe pulsar para obtener la fotografía de la obra en cuestión.
La Universidad de Jaén, por su parte, dispone de una página (http://www.ujaen.es/jaen/index.html) con una guía en la que puede encontrarse información turística y cultural de toda la provincia. A través de ésta es posible acceder a sitios Web de itinerarios culturales, rutas de arte y artesanía o información de museos, entre otros, desarrollados por diversas instituciones.

De ellos destaca "Jaén en 48 horas", también de la Universidad de Jaén, que a través de un índice inicial propone diversas rutas artísticas, religiosas, ecológicas, gastronómicas, etc. En concreto, hemos escogido la "Ruta del Renacimiento" (http://www.ujaen.es/jaen/jaen48h/guia04.html, que se centra en Baeza y Úbeda, ciudades con destacados ejemplos de la arquitectura renacentista en Andalucía.

Estos itinerarios virtuales por las dos ciudades jiennenses ofrecen un amplísimo volumen de información de su patrimonio monumental y una minuciosa descripción del recorrido, con el único inconveniente de la ausencia de imágenes fotográficas y de un diseño abigarrado que no se adecúa al estilo habitual de la información en Internet.

Por último, el Patronato de Promoción Provincial y Turismo de Jaén (http://www.promojaen.es/) dispone de una moderna y atractiva página en Internet y propone opciones interesantes.
Por un lado, a través del botón "Baeza y Úbeda, Patrimonio de la Humanidad" encontramos un apartado creado para apoyar y justificar la candidatura de estas ciudades a integrarse en la Lista del Patrimonio de la Humanidad de la UNESCO. Además de destacar sus valores patrimoniales excepcionales, en esta sección se especifica la superficie de los conjuntos monumentales propuestos para su inclusión, las zonas que abarcan, etc., así como los objetivos que se persiguen con la solicitud de ser declaradas como Patrimonio de la Humanidad.

Por otro lado, utilizando el botón de "Turismo cultural" nos encontramos con una más amplia gama de posibilidades y con un diseño mucho más atractivo y actualizado, que permite navegar de forma ágil y sencilla por las distintas secciones de la página Web. Así, sirvan como ejemplo los botones dedicados a las "Ciudades monumentales", donde volvemos a encontrar Úbeda y Baeza, a los "Monumentos BIC" o a las "Rutas culturales".

En todos los casos aparecen los textos descriptivos de los lugares y obras a los que se hace referencia, acompañados de diversas fotografías. Además, se ofrece la posibilidad de acceder a los planos de los centros históricos y a imágenes de vídeo de las zonas descritas.

María Victoria Madrid Díaz Centro de Documentación del IAPH

\title{
Direcciones web de interés sobre Itinerarios y Rutas Culturales por Andalucía y España
}

\section{ITINERARIOS CULTURALES POR ANDALUCÍA}

\section{Bienvenido a TurAndalucía} http://www.turandalucia.com

Sitio con una alta calidad gráfica y visual, que informa al visitante sobre posibles rutas a seguir según el tema elegido. Asimismo, da información geográfica sobre las provincias, sitios con encanto, legados históricos, pueblos, etc.

\section{Itinerario de Almorávides y \\ Almohades entre Andalucía y \\ Marruecos \\ (Legado Andalusí) \\ http://www.legadoandalusi.es/ \\ itinerarios.htm}

Itinerario entre Andalucía y Marruecos. Se accede a través de un mapa sensible dividido según las zonas en 7 itinerarios distintos donde se destacan aspectos históricos y artísticos de la zona, entre otros.

\section{La Sevilla Histórica}

http://www.disbumad.es/sevilla/historia/

Recorrido por Sevilla Capital, siguiendo sus etapas históricas.

\section{Las Rutas del Legado Andalusí}

http://www.legadoandalusi.es/rutas/rutas.htm Se nos presentan una serie de rutas históricas de la época ,entre Granada y Algeciras, Córdoba, Lisboa, Murcia, Navas de Tolosa,Sevilla o Tánger. 


\section{Ruta Bética-Romana}

http://www.betica-romana.org/

Recorrido por doce ciudades de las provincias de Cádiz, Córdoba y Sevilla en la época de la Hispania Romana.

\section{Rutas Turísticas por Almería}

http://www.almeria.net/almeria/turismo/rutas/ Con distintos itinerarios por la capital y el levante almeriense entre otras, todas ellas acompañadas de mapas de situación.

\section{Serrania de Ronda}

http://www.serraniaronda.org/

Con una completa información sobre el entorno natural, monumental y turístico de la comarca.

\section{Turista Virtual de Carmona} http://www.andal.es/carmona/

Un paseo virtual por dicha ciudad con plano interactivo, información sobre monumentos, fiestas y un paseo virtual

Visita a la Santa Capilla de San Andrés de Jaén

http://personal5.iddeo.es/icuesta/page2.htm

Un recorrido detallado por todas sus dependencias, con un plano de situación y fotografías de todos sus lugares.

\section{ITINERARIOS CULTURALES POR EL RESTO DE ESPAÑA}

\section{Aragón, el Mudéjar, Goya}

http://aragonesasi.com/aragon.htm

Información sobre sus provincias, sus comarcas, su historia y su arte, así como mapas detallados de la zona.

Asturias Turística, Buscador de recursos turísticos

http://turismo.asturnet.es/

Una web interesante, ya que presenta una amplia información sobre rutas, monumentos, paisajes naturales, etc, a través de un buscador por el que podemos elegir la comarca y el tipo de información que buscamos de forma personalizada.

\section{Castillos medievales de Guadalajara} http://www.esfera.com/castillos/castillos.htm Una amplia información geográfica, artística e histórica de todos los castillos de la provincia.

\section{Cincuenta Rutas por Galicia}

http://www.galiciaonline.es/

Todo lo que se puede buscar sobre Galicia: rutas específicas por las comarcas, rutas artísticas, información geográfica de todas las ciudades, la cultura, los puertos, etc. Además cuenta con un buscador.

\section{Excursiones inéditas desde Madrid}

http://www.sinix.net/paginas/rutas/

Una web que propone en principio tres itinerarios interactivos para realizar desde Madrid a través de un mapa del país, todas ellas basadas en tres libros de rutas por España.

\section{La Mancha en la Red}

http://web.jet.es/plopezp/molinos/lamancha.h tm\#Rutas

Con información sobre sus localidades, su cultura y paisajes, así como de distintas rutas turísticas por sus tierras.

\section{La Ruta del Cid en bicicleta}

http://www.revistaiberica.com/Rutas_y_destinos/cl/cid/index.htm

Toda la información para hacer la ruta del Cid en bicicleta desde Burgos a Valencia: etapas, reportajes, fotos, recomendaciones, etc

\section{Las ciudades y villas del Camino de} Santiago

http://www.ciudadfutura.com/xacobeo/ciudades.htm

Un recorrido por las grandes ciudades que se encuentran a lo largo del camino de Santiago: aspectos artísticos, foros de opinión,etc.

\section{Monasterios medievales de Guadalajara}

http://www.aache.com/monaster/

Con amplia información gráfica y textual de los monasterios todavía vivos y de los que están en ruinas de la provincia de Guadalajara.

Románico en las provincias de Segovia, Avila, Guadalajara y Burgos http://www.arrakis.es/ garma/index0.htm Un recorrido por los monumentos del románico castellano en las distintas ciudades de Castilla y León.

\section{Ruta Cervantina}

http://www.diputoledo.es/Provinci/cervante.htm Ruta temática por distintos parajes y pueblos de la Mancha.

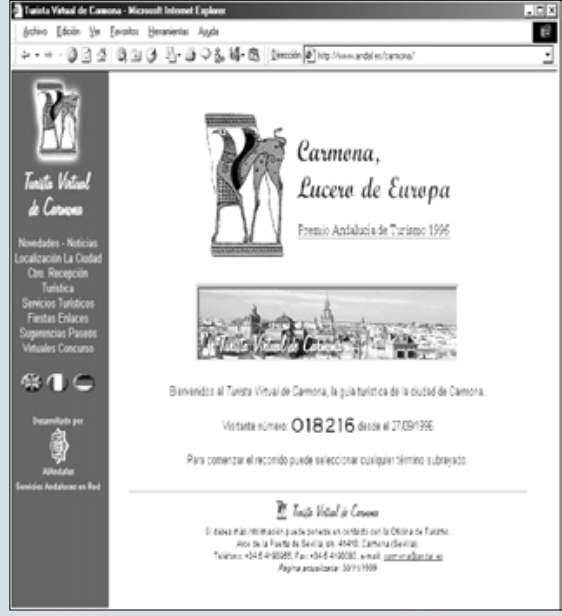

\section{Ruta de los Castillos de Toledo}

http://www.diputoledo.es/Provinci/castillo.htm Una interesante ruta por los castillos de la provincia de Toledo, divididos entre los castillos del norte, del sur y del este, mostrando también la distribución geográfica de los mismos.

\section{Rutas de Cantabria}

http://turismo.cantabria.org/sitesp/derecho.ht $\mathrm{m}$ ? tema $=$ geo $\&$ loc $=00$

Con un buscador geográfico por zonas y comarcas y con una amplia información sobre el arte, la cultura,la geografía y el turismo rural entre otros.

\section{Rutas en bici por los alrededores de} Valladolid

http://www.fortunecity.com/greenfield/profit/3 I 7/PRINCIPAL.htm

9 rutas en bici por la provincia, acompañadas de una amplia explicación textual y de un plano detallado de los caminos y sus recorridos.

\section{Talavera de la Reina y su entorno (Toledo)}

http://www.diputoledo.es/Provinci/talavera.html Un recorrido por los aspectos históricos, artísticos y arquitectónicos de la comarca. Asimismo, cuenta con un plano de situación de los monumentos más emblemáticos de la ciudad.

\section{Todo sobre España}

http://www.red2000.com/spain/lindex.html Información sobre todas sus regiones y sus ciudades con datos geográficos, demográficos, e histórico-asrtísticos de gran interés. 